\title{
Oral Health Practices And Status Of 12-Year-Old Pupils In The Western Region Of Cameroon
}

\author{
A.M. Agbor and T.R. Kuimo
}

\section{ABSTRACT}

Introduction. Dental caries, though common, presents with considerable variation in occurrence between countries, regions within countries, areas within regions, and among social and ethnic groups. The aim of this study was to describe the oral health status and practices of primary school children in the western region of Cameroon. Methods. This was a comparative descriptive cross sectional study took place in April to October 2018 in primary schools located in three localities (Urban, semi urban and rural) of the West region of Cameroon using a multistage random (cluster) sampling technique. Results. There were a predominance of female pupils 265(54.9\%) than males 218 (45.1 $\%)$ and $411(85.1 \%)$ of the pupils had toothbrushes with the majority from urban areas $142(94.7 \%)$. The frequency of brushing was higher in urban than the semiurban and rural areas and 212(50.5) of them brushed teeth once a day and nearly half 184(43.8) twice daily. More than half 238(56.7) of the children brush before breakfast, less than half $176(42 \%)$ brush after supper. Two third $280(66.8 \%)$ of the children brush their teeth with toothbrush and paste. Those who brush without toothpaste 54 (39.4\%) were mainly in rural areas. Wood ash 7(5.1\%), soap $4(2.9 \%)$ and chewing sticks $3(2,2 \%)$ were used for brushing in rural areas, $395(82 \%)$ of the children had plaque, $73(15.1 \%)$ presented with dental mal positions, 341(70.6\%) with bleeding gums and 223(46.2\%) had calculus especially in the lower incisors. The prevalence of dental caries in the entire population was $28.1 \%, 346(71.6 \%)$ were caries free and $01(0.2 \%)$ had a missing tooth due to decay. None of the children presented with filled teeth. The mean DMFT was higher in the rural (0.39) as compared to the semi urban $(0.18)$ and the urban (0.09) respectively. The mean DMFT index of the entire population was 0.28 while $135(27.9 \%$ ) of the pupils presented with enamel caries especially in the first permanent molar, 19(47.2\%) presented with deep caries mostly in the second deciduous molars and $8(22.5 \%)$ presented with enamel caries on the second deciduous molars. Dental trauma $12(2.5 \%)$ was mostly found in the upper central incisors. More than a third 61(36.1\%) of the pupils who presented with gingivitis were from rural areas, 43(25.4\%) from semi urban, and 40(26.7\%) from urban areas. Almost all the children who lived in semi-urban 157(92.9\%) and in urban areas 150 (78.7\%) consumed cariogenic diets. A third of the children who ate in-between meals lived in urban areas $149(34.2 \%)$. Conclusion. The prevalence of dental caries, periodontal diseases and other orofacial lesions in the western region of Cameroon is low. Tooth brushing without toothpaste was predominant in rural areas. Dental caries was found to be higher in rural and urban areas. Recommendation. Collaboration between the ministries of health and basic education is necessary as a measure to institute oral health education in primary schools. This will go a long way to reduce inequalities in oral health by improving in the oral practices.

Key words: Oral health status, hygiene practices, Caries, pupils, Western region, Cameroon.

\section{INTRODUCTION}

Poor oral health affects the quality of life and is been linked to many diseases affecting humans. Chronic diseases that affect children require significant adjustments in life leading to decreased quality of life. Among the most prevalent diseases of childhood are dental caries, asthma, diabetes, and obesity. Dental caries presents 5 to 8 times more frequently than asthma, the second-most common condition in children [1].Dental caries, though common, presents with considerable variation in occurrence between countries,
Published Online: January 11, 2020

DOI : 10.24018/2020.1.1.1

\section{A.M. Agbor *}

School of Dentistry, Faculty of Health and biomedical sciences

Université des Montagnes, Cameroon. (agborasm@yahoo.com).

\section{T.R. Kuimo}

School of Dentistry, Faculty of Health and biomedical sciences

Université des Montagnes, Cameroon. (e-mail: raissakuimo@gmail.com )

*Corresponding Author regions within countries, areas within regions, and among social and ethnic groups [2]. It is one of the most prevalent chronic diseases affecting children in Sub-Saharan Africa with a higher prevalence in children from low socioeconomic backgrounds [3]. This high prevalence has been invariably attributed on the presence of high plaque deposits on the tooth surfaces as a result of poor or inefficient oral hygiene practices. Optimal oral hygiene practices are instrumental to achieving good dental and gingival health. However, optimal oral hygiene practices are hindered by 
poverty, ignorance, misinformation, erroneous beliefs, cultural and religious practices [4]. Amongst the determinants of oral hygiene practices, the quality of cleaning is the most important, It has been reported that the quality of the cleaning appears to be more important than the frequency of its performance. Professional tooth cleaning at regular intervals may inhibit caries on all tooth surfaces. The effect of selfperformed oral hygiene has been demonstrated mainly on free smooth surfaces and on front teeth [5].

In children, the age of 12 years is a landmark age, which marks an important step in the dental growth and development especially when the child transit from mixed to permanent dentition. Therefore, good oral hygiene practices at mixed dentition is important to maintain caries free teeth at adulthood. In Cameroon, information of the oral health status of children at this age is scanty. The purpose of this study was to compare the oral health status and practices of 12-year old children in three locations in the Western Region of Cameroon.

\section{METHODS}

This was a descriptive cross sectional study that took place in April to October 2018. The study was carried out on 12 year old primary school children attending schools located in three selected localities (Urban, semi urban and rural) of the West region of Cameroon using a multistage random sampling technique.

The schools were randomly selected and were divided into 3 groups;

i. Rural area represented by Bameka a village of the district of Bamendjou in the division of Hautplateaux, with an estimated population of 17000 and $62 \mathrm{~km}$ from Bafoussam the capital city of the west region of Cameroon.

\section{ii. Semi-urban} by Bangangté, capital of division, populated inhabitants (2011).

iii. Urban area represented Bafoussam, political and economic capital of the Western region and the the Mifi division, a population of about 347517 inhabitants (2008) (4).

\section{Sampling}

Multistage sampling techniques was employed in this study. In the first stage, the seven divisions that make up the Western region were arranged in alphabetical order. Two yes and five no responses were kept in a box and seven patients attending the Universite des Montagnes dental clinic assisted in picking the responses. The first picked response corresponded to the first division in alphabetical order while the last picked response corresponded to the last division in alphabetical order. At the end of the exercise, Mifi and Nde divisions were selected.

At the second level of sampling, convenience sampling technique was employed in selecting the schools in the divisional headquarters to get a large population and to facilitate the inclusion of rural and urban schools in the study. Bafoussam and Bangangte which are the divisional headquarters of Mifi(Urban) and Nde (semi-urban) were selected. A list of villages that are at least $50 \mathrm{~km}$ away from the urban center was to select a village that will be used to represent a rural area using random sampling .

In each of the schools, all the 12-13 years old children were included to make it a large study population using a school register. The children that did not assent to the study, those that could not provide parental or guardian permission (consent) and those that reported suffering from chronic systemic diseases were excluded. A systematic sampling technique was used in selecting the participants by selecting name after every 4 names using a school register.

\section{Data collection tool/procedure}

Data was collected through interviewer administered questionnaire and clinical oral examination was carried out by a trained clinician under bright light. The questionnaire elicited information on the social and demographic profile of the children, frequency and reasons for tooth cleaning, type tooth cleaning devices and source of information on oral selfcare. This questionnaire was pre-tested among school children from the non-selected schools in the region. Dental surgeons who were trained and calibrated before the start of survey examined and recorded the findings.

Extra oral examination was used to evaluate the facial profile and asymmetry, lip competence scarification marks, wounds e,t,c Intra oral examination was used to look for lesions in the intra-oral environments and the DMFT and the CPITN indices were used for measuring dental caries experience and periodontal health respectively in the study population.

The status of gingiva was examined on the buccal, lingual mesial and distal teeth with gingival index with scoring as follows: 1. mild inflammation, 2. moderate inflammation; 3 . severe inflammation. The score for each individual was gotten by adding all the gingival score and dividing it by the total number of teeth multiplied by four (4). The status of gingival health was subsequently categorized based on the gingival score as 0 , normal gingival; $0.1-1$, mild gingivitis; .1-2.0, moderate gingivitis; $2.1-3.0$, severe gingivitis.

\section{Data analysis}

A data template was created in Epi info 7.1.3 and data was directly introduced into the data base for analysis using Epi info 7.1.3. Test of association was done using Chi Square statistics and $\mathrm{P}<0.05$ was considered as statistical significance.

\section{Ethical considerations}

This study received the Ethical Clearance from the universite des Montagnes institutional review board, the Regional Delegation of Basic Education and Medical confidentiality was preserved.

\section{RESULTS}

We consulted 528 pupils and retained 483 pupils making the response rate to $91.7 \%$ aged 12 years meeting the inclusion criteria. There were a predominance of female pupils 265(54.9\%) than females 218 (45.1\%) (Table I).

Table I. Location and gender of pupils. 


\section{Extraoral exam}

The majority $440(91.1 \%)$ of the children's facial appearance was normal, $24(5 \%)$ presented with scarifications in the neck and face, wounds at the labial commissures $7(1.4 \%)$ and $12(2.5 \%)$ scars on the face.

Intraoral examination.

More than three quarters $425(88 \%)$ of the children presented with normal occlusion,53(8.9\%) presented with distoocclusion, $15(3.1 \%)$ with mesio-occlusion (Table II).

Table II. Occlusions

\begin{tabular}{|l|l|}
\hline Occlusion & N (\%) \\
\hline Class I occlusion (normocclusion) & $425(88 \%)$ \\
\hline Occlusion class II (distocclusion) & $43(8.9 \%)$ \\
\hline $\begin{array}{l}\text { Occlusion class III (mesio- } \\
\text { occlusion) }\end{array}$ & $15(3.1 \%)$ \\
\hline
\end{tabular}

Oral hygiene Status.

More than three quarters $411(85.1 \%)$ of the pupils had tooth brushes. The majority of the pupils who had tooth brushes where from urban areas $142(94.7 \%)$. The frequency of brushing was higher in urban than the semi-urban and rural areas. Half $212(50.5)$ of them brushed teeth once a day and nearly half 184 (43.8) twice daily (Table III).

Table III: Oral hygiene practice.

\begin{tabular}{|l|c|c|c|c|}
\hline \multicolumn{1}{|c|}{$\begin{array}{l}\text { Hygiene } \\
\text { concepts }\end{array}$} & $\begin{array}{c}\text { Rural } \\
\text { N (\%) }\end{array}$ & $\begin{array}{c}\text { Semi- } \\
\text { Urban } \\
\text { N (\%) }\end{array}$ & $\begin{array}{c}\text { Urban } \\
\text { N (\%) }\end{array}$ & $\begin{array}{c}\text { TOTAL } \\
\text { N (\%) }\end{array}$ \\
\hline $\begin{array}{l}\text { Tooth brush } \\
\text { usage }\end{array}$ & $134(81.7)$ & $135(79.9)$ & $142(94.7)$ & $411(85.1)$ \\
\hline $\begin{array}{l}\text { Brushing } \\
\text { frequency }\end{array}$ & \multicolumn{5}{|l}{} & $212(50.5)$ \\
\hline $\begin{array}{l}\text { 1(once a day) } \\
\text { 2(Twice a }\end{array}$ & $57(41.6)$ & $64(45.7)$ & $63(44.1)$ & $184(43.8)$ \\
day) & & & & \\
\hline
\end{tabular}

More than half 238 (56.7) of the children brush before breakfast wake up less than half brush 176 (42\%) brush after supper.(Table IV).

Table IV. Period and frequency of brushing.

\begin{tabular}{|l|l|l|l|l|}
\hline $\begin{array}{l}\text { Brushing } \\
\text { moment }\end{array}$ & $\begin{array}{l}\text { Rural } \\
\text { N (\%) }\end{array}$ & $\begin{array}{l}\text { Semi- } \\
\text { urban } \\
\text { N (\%) }\end{array}$ & $\begin{array}{l}\text { Urban } \\
\text { N (\%) }\end{array}$ & $\begin{array}{l}\text { TOTAL } \\
\text { N (\%) }\end{array}$ \\
\hline $\begin{array}{l}\text { After } \\
\text { breakfast }\end{array}$ & $1(0.7)$ & 0 & $1(0.7)$ & $2(0.5)$ \\
\hline $\begin{array}{l}\text { Before } \\
\text { bedtime /after } \\
\text { supper }\end{array}$ & $52(38)$ & $60(42.9)$ & $64(45.1)$ & $176(42.1)$ \\
\hline $\begin{array}{l}\text { Before } \\
\text { breakfast }\end{array}$ & $83(60,6)$ & $79(56.4)$ & $72(53.5)$ & $238(56.7)$ \\
\hline After launch & $1(0.7)$ & $1(0.7)$ & $1(0.7)$ & $3(0.7)$ \\
\hline
\end{tabular}

\begin{tabular}{|l|l|}
\hline Location & $\mathbf{N}(\%)$ \\
\hline Bafoussam (Urban) & $150(31 \%)$ \\
\hline Bangangte (semi-Urban) & $169(35 \%)$ \\
\hline Bameka (Rural) & $164(34 \%)$ \\
\hline Gender & \\
\hline Female & $218(45.1 \%)$ \\
\hline Male & $265(54.9 \%)$ \\
\hline
\end{tabular}

Two third 280(66.8\%) of the children brush their teeth with toothbrush and toothpaste, 101(24.1\%), the frequency of brushing is 68(49.7\%) lowest in the rural areas as compared to the urban areas $113(79.6 \%)$. Tooth brushing without tooth paste $54(39.4 \%)$ was higher in rural areas. Wood ash7 $(5.1 \%)$, soap 4(2.9\%) and chewing sticks 3(2, 2\%) were most frequently used in rural areas (Table V).

\begin{tabular}{|c|c|c|c|c|}
\hline $\begin{array}{l}\text { Brushing } \\
\text { type }\end{array}$ & $\begin{array}{l}\text { Rural N } \\
(\%)\end{array}$ & $\begin{array}{l}\text { Semi } \\
\text { urban } \\
\text { N }(\%)\end{array}$ & $\begin{array}{l}\text { Urban } \\
\text { N }(\%)\end{array}$ & $\begin{array}{r}\text { TOTAL } \\
\text { N (\%) }\end{array}$ \\
\hline $\begin{array}{l}\text { Brush and } \\
\text { toothpaste }\end{array}$ & $68(49.7)$ & $99(70.7)$ & $113(79.6)$ & $280(66.8)$ \\
\hline $\begin{array}{l}\text { Brush without } \\
\text { toothpaste }\end{array}$ & $54(39.4)$ & $25(17.9)$ & $22(15.5)$ & $101(24.1)$ \\
\hline Wood Ash & $7(5.1)$ & $6(4,3)$ & $4(2.8)$ & $17(4,1)$ \\
\hline Soap & $4(2.9)$ & $3(2,1)$ & $3(2,1)$ & $9(2,4)$ \\
\hline $\begin{array}{l}\text { Chewing } \\
\text { stick }\end{array}$ & $3(2,2)$ & $1(0.7)$ & 0 & $4(1)$ \\
\hline Charcoal & 0 & $3(2,1)$ & 0 & $3(0.7)$ \\
\hline Salt & 0 & $2(1,4)$ & 0 & $2(0.5)$ \\
\hline Fingers & 0 & $1(0.7)$ & 0 & $1(0.2)$ \\
\hline $\begin{array}{l}\text { Traditional } \\
\text { products }\end{array}$ & $1(0.7)$ & 0 & 0 & $1(0.2)$ \\
\hline
\end{tabular}

Duration of brushing.

More than a third $(34.6 \%)$ of the children brush more than 3 minutes and less than a third in an average of 2 minutes (28.6\%).(Figure 1).

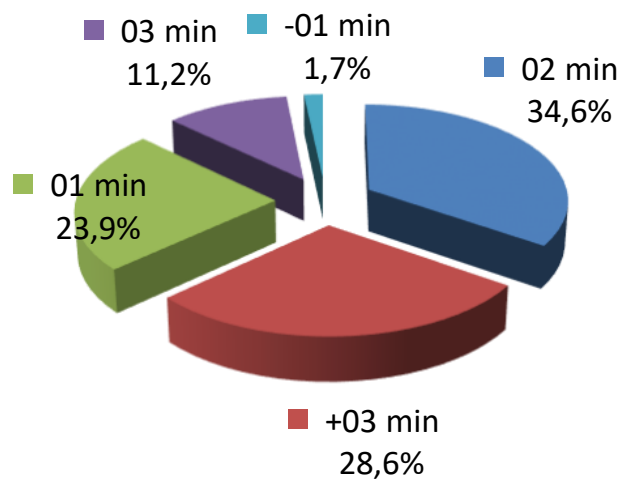

Figure 1. Mean brushing time. 
Intra oral examination.

Less than a fifth $73(15.1 \%)$ of the children presented with dental mal positions.

Oral hygiene

More than three quarters $395(82 \%)$ of the children had plaque and $341(70.6 \%)$ presented with bleeding gums. Calculus was present in $223(46.2 \%)$ and was predominant in lower incisor.

Dental carious challenge

The prevalence of dental caries in the entire population was $28.1 \%$.The majority of pupils $346(71.6 \%)$ had no caries, $01(0.2 \%)$ child had a missing tooth due to decay. None of the children presented with filled teeth. The mean DMFT was higher in the rural (0.39) as compared to the semi urban (0.18) and the urban 0.09. The mean DMFT index of the entire population was 0.28 . $\mathrm{P}$ - value $=0.43$. $($ Table VI).

Table VI. DMFT index based on localities.

\begin{tabular}{|l|l|l|l|l|}
\hline $\begin{array}{l}\text { DMFT } \\
\text { teeth }\end{array}$ & $\begin{array}{l}\text { Rural } \\
(\%)\end{array}$ & $\begin{array}{l}\text { Semi } \\
\text { urban } \\
(\%)\end{array}$ & Urban N (\%) & TOTAL (\%) \\
\hline $\mathbf{0}$ & $103(62.8)$ & $137(81.5)$ & $106(70)$ & $346(71.6)$ \\
\hline $\mathbf{1}$ & $27(16.5)$ & $15(8,9)$ & $17(11.3)$ & $59(12.2)$ \\
\hline $\mathbf{2}$ & $13(7,9)$ & $8(4.8)$ & $17(11.3)$ & $38(7,9)$ \\
\hline $\mathbf{3}$ & $10(6,1)$ & $4(2,4)$ & $1(0.7)$ & $15(3,1)$ \\
\hline $\mathbf{4}$ & $7(4,3)$ & $1(0.6)$ & $4(2.7)$ & $12(2.5)$ \\
\hline $\mathbf{5}$ & 0 & $2(1,2)$ & $4(2.7)$ & $6(1,2)$ \\
\hline $\mathbf{6}$ & $2(1,2)$ & 0 & $1(0.7)$ & $3(0.6)$ \\
\hline $\mathbf{8}$ & $2(1,2)$ & $1(0.6)$ & $1(0.7)$ & $4(0.8)$ \\
\hline $\begin{array}{l}\text { Mean } \\
\text { DMFT }\end{array}$ & 0.37 & 0.18 & & \\
\hline
\end{tabular}

More than a quarter $135(27.9 \%)$ of the pupil presented with enamel caries which was predominates in the first permanent molar. Almost half of the pupils $19(47.2 \%)$ presented with deep caries mostly in the second deciduous molars and $8(22.5 \%)$ presented with enamel caries on the second deciduous molars. Dental trauma $12(2.5 \%)$ was mostly found in the central incisors.(Table VII).

Table VII. Dental caries and trauma.

\begin{tabular}{|l|l|l|l|l|}
\hline interested teeth & $\begin{array}{l}\text { Enamel } \\
\text { caries } \\
\text { N }(\%)\end{array}$ & $\begin{array}{l}\text { Deep } \\
\text { caries } \\
\text { N }(\%)\end{array}$ & $\begin{array}{l}\text { No caries } \\
\text { N (\%) }\end{array}$ & $\begin{array}{l}\text { Trauma } \\
\text { N (\%) }\end{array}$ \\
\hline $\begin{array}{l}\text { First permanent } \\
\text { molar }\end{array}$ & $135(27.9)$ & $47(9.7)$ & 0 & 0 \\
\hline $\begin{array}{l}\text { Second permanent } \\
\text { premolar }\end{array}$ & $4(0.8)$ & 0 & $1(0.2)$ & 0 \\
\hline $\begin{array}{l}\text { First Permanent } \\
\text { premolar }\end{array}$ & $2(0.4)$ & $2(0.4)$ & 0 & 0 \\
\hline Permanent canine & $1(0.2)$ & $1(0.2)$ & 0 & 0 \\
\hline
\end{tabular}

\begin{tabular}{|l|l|l|l|l|}
\hline $\begin{array}{l}\text { Permanent central } \\
\text { incisor }\end{array}$ & $16(4.7)$ & 0 & 0 & $12(2.5)$ \\
\hline $\begin{array}{l}\text { Second } \\
\text { deciduous molar }\end{array}$ & $8(22.5)$ & $19(47.2)$ & $1(4)$ & 0 \\
\hline $\begin{array}{l}\text { First deciduous } \\
\text { milk ere }\end{array}$ & 0 & $1(25)$ & 0 & 0 \\
\hline Deciduous canine & 0 & $2(40)$ & 0 & 0 \\
\hline $\begin{array}{l}\text { Second deciduous } \\
\text { incisor }\end{array}$ & 0 & $1(50)$ & 0 & 0 \\
\hline
\end{tabular}

\section{Periodontal diseases.}

More than a third 61(36.1\%) of the pupils who presented with gingivitis were from rural areas, $43(25,4 \%)$ from semi urban, and $40(26.7 \%$ ) from urban areas.(Figure 2).

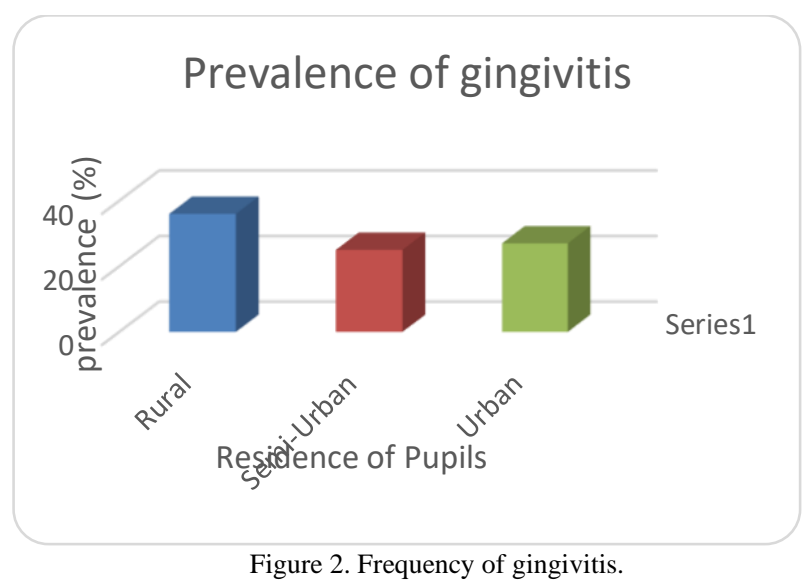

Almost all the children 157(92.9\%) lived in semi-urban areas, three quarters $150(78.7 \%)$ in urban consumed cariogenic diets. A third of the children who eat in between meals lived in urban areas $149(34.2 \%)$. Three quarters $123(72.8 \%)$ of the children in semi-urban areas were conscious of their oral hygiene, and more than half 61 (37.2\%) of the children's food are controlled by the parents.

(Table VIII).

\begin{tabular}{|l|l|l|l|l|}
\hline Risk factors & $\begin{array}{l}\text { Rural } \\
\mathbf{N}(\%)\end{array}$ & $\begin{array}{l}\text { Semi } \\
\text { urban } \\
\mathbf{N}(\%)\end{array}$ & $\begin{array}{l}\text { Urban } \\
\mathbf{N}(\%)\end{array}$ & $\begin{array}{l}\text { TOTAL } \\
\text { N(\%) }\end{array}$ \\
\hline Cariogenic diet & $53(32.2)$ & $157(92.9)$ & $150(78.7)$ & $\begin{array}{l}270(119, \\
1)\end{array}$ \\
\hline $\begin{array}{l}\text { Snacks between } \\
\text { meals }\end{array}$ & $126(28.9)$ & $161(36.9)$ & $149(34.2)$ & $436(90.3)$ \\
\hline $\begin{array}{l}\text { Awareness } \\
\text { the oral hygiene }\end{array}$ & $41(25)$ & $123(72.8)$ & $19(12.7)$ & $183(37.9)$ \\
\hline $\begin{array}{l}\text { Parents } \\
\text { controlling food } \\
\text { at school }\end{array}$ & $61(37.2)$ & $43(25.4)$ & $45(30)$ & $149(30.8)$ \\
\hline
\end{tabular}

Dental consultation : $\quad$ Only $37(7.7 \%)$ of the children have done have ever been to a dentist and the consultation rate is higher in Bangangte 19 (11.2\%). Reasons for not consulting

Ignorance of dentistry for $408(84.5 \%)$ of these children is the major reason for non-dental consultation. 


\section{DISCUSSION}

This study compared the oral health status of the three different tiers of the population of the western of Cameroon. It showed that though the caries challenge of the rural communities is higher than the semi urban and urban communities irrespective of the high consumption of refined sugar in the urban and the semi urban communities. This might be due to absence of oral health care personnel's or primary oral health care personnel's in rural areas making access to oral care facilities for preventive treatment and adequate oral health education. Agbor and collegues (2018) reported a large discrepancy in the distribution of the oral health workforce in Cameroon as nearly all the dentists (93.26\%) resided in urban areas of the country [5]. In Cameroon these inequalities has been reported to be pronounced in the oral health care than other domain of health care as 80 percent of oral health care personnel are located in the 2 major cities of Douala and Yaoundé $[6,7,8]$. The current study showed a predominance of female children than the males. This corresponds to a similar study reported in Cameroon by Azodo and Agbor (2015) who stated that females are predominant in primary schools [9]. It also reflects the demographic profile of Cameroon $[9,10]$.

Oral hygiene

The current study demonstrated that oral health care awareness is well developed in half of the population though in two thirds of the population brushing is not supervised. This can be explained by the fact that oral health educational level of the parents is low and parents consider that children of school age are independent.

\section{Prevalence of carious pathology and periodontal disease}

The current study showed that almost half of the pupils had toothaches as a result of dental caries and a third had decayed teeth. Compared with studies conducted among school children in a rural areas in the North-West of the country by Attin et al.(1999), this rate is low because the prevalence of caries was $78 \%$ for $9-12$ years [11]. Their report was extremely high prevalence of dental caries especially in a rural area where the prevalence of dental caries is low. In the current study, the rural areas recorded the highest DMFT score of dental caries though the overall dental caries challenge was low. This is because the dietary habits in rural areas is different from that of urban areas where natural food rich in fibers and unrefined carbohydrates are consumed as compared to the refined carbohydrates consumed in semiurban and urban areas. Of the many factors that contribute to the development of dental caries, diet plays an important role [12]. The role of sugar (and other fermentable carbohydrates such as highly refined flour) as a risk factor in the initiation and progression of dental caries is overwhelming [10]. It has been observed that the consumption of sugar in rural communities in Cameroon is on the increase. This is because of easy accessibilities of roads and also bakeries are trying to expand their markets to remote areas making refined carbohydrates available to rural communities in the form of bread ,pastries and confectioneries easily accessible. Besides, in rural areas, the consumption of sugary food is seen as a form of civilization.

In the current study, almost all the children living in semiurban areas and three quarters in urban consumed cariogenic diets while a third of the children who lived in urban areas, eat between meals. This explains the high prevalence of dental caries in the semi-urban areas of Cameroon. The low carious challenge in the urban and semi urban communities can be as a result of high oral health awareness in primary schools in this region. Cameroon is one of the countries undergoing epidemiological transformation with more people from the younger generation migrating to urban areas. The current study also demonstrated that the control of the sales of cariogenic food in the school premises in all the 3 areas was low. This gives the children no other option than to take cariogenic food to schools. This is confirmed by the fact that children in semi-urban and urban areas snack in between meals more than children in rural areas.

Only one third of these children were sensitized on oral hygiene and $80.5 \%$ had an apprenticeship on how to brush their teeth, mostly by their parents when they were "small". As time passes, parents are concerned about the future of their children, but neglect their oral health.

The teeth most affected by enamel caries are the first molars, specifically tooth 36 and then teeth 46 and 26 . This can be explained by the fact that these are the first permanent teeth to erupt in the mouth when the manual dexterity of the child is not well developed thereby affected by improper brushing. The high prevalence of dental caries on the second molars (\#17 and \#37) also reflected the poor oral hygiene of the children.

\section{Gingival health}

The prevalence of gingivitis in the current study was $29.4 \%$. This corresponds to a study carried out in Cameroon by Azodo and Agbor (2015) who reported that out of 2287 school children examined, $1676(73.3 \%)$ had normal gingivae while $26.7 \%$ had gingivitis of varying severity. The gingivitis was found significantly more in rural dwellers $(\mathrm{P}=0.001)$ [3]. They concluded that though the majority of the participants had received instruction on how to care for their teeth and the predominant source of this instruction was from their parents. They concluded that irregular teeth cleaning among the children was the major cause of gingivitis [3].

\section{Risk factors for oral pathologies.}

The consumption of refined sugar especially bet ween meals has been associated with dental caries [12]. Snacking between meals was higher in the study as the majority of the pupils snacked between meals. The result of the current study was very high as compared to a study done in DRC Congo in 2008 where two-thirds of the children snacked between meals [13]. This high snacking between meals is a reflection of the socio economic growth of population with an increase of their standard of living, increase publicity in both the social and the mainstream media. In the current study, two thirds of the children with cavities affirmed they snacked between meals. Though dental caries is a disease of multi-factorial origin, the high snacking reported in our study confirmed that snacking between meals is a major risk factor in dental caries.

Dental attendance: The oral health-seeking behaviour in many developing countries varies with the various regions of the countries. This is because of lack education and availability of services. Rural areas in these countries and poorer sections of the population in urban areas often do not have access to oral health services mainly because of inaccessibility to dentists and the high costs of care [5]. The current study also showed that the oral health seeking behavior of the majority of the children was very low. This 
can be attributed to ignorance on the role of dentistry in their health care needs, poor access to oral health care facilities and the use of alternative or complementary medicine.

\section{CONCLUSION}

The prevalence of dental caries, periodontal diseases and other orofacial lesions in the western region of Cameroon was low. The majority if the pupils did not have dental caries and have not lost a tooth as a result of dental caries. Tooth brushing without toothpaste was predominant in rural areas as reflected in this by the fact that dental caries was found to be higher in rural and urban areas. Insufficient oral hygiene practices both in schools and at home, bad dietary practices and poor access to oral health care facilities were factors responsible for these orofacial disease morbidities.

\section{RECOMMENDATIONS}

Oral health care professional and policy makers should set up programs that will target under-privileged population.

The ministry of health should work in collaboration with the ministry of basic education and other stakeholders should institute cost effective oral health care programs in schools and should target not only pupils, but teachers and school authorities especially in the rural areas where resources are limited.

\section{REFERENCES}

1. S.L.Jackson, W.F. Vann, J.B. Kotch, B.T. Pahel, J.Y. Lee (2011). Impact of Poor Oral Health on Children's School Attendance and Performance. American Journal of Public Health.101(10).pp.19001906.

2. B.L. Edelstein (2005). Pediatric caries worldwide: implications for oral hygiene products. Compend Contin Educ Dent . 26 (5 S uppl 1).pp 4-9.

3. C.C. Azodo, M.A. Agbor (2015). Gingival health and oral hygiene practices of schoolchildren in the North West Region of Cameroon. BMC Res Notes. Pp.8:385.

4. H.T. Bellini, P. Arneberg, R, Frithjof (1981). Oral hygiene and caries, Acta Odontologica Scandinavica.39:5.pp 257-265.

5. B.T. Mafuvadze, L.B. Mahachi, Mafuvadze (2013). Dental caries and oral health practice among 12 year old school children from low socioeconomic status background in Zimbabwe. The Pan African Medical Journal.14:164.14.pp.164.2399.

6. J.P. Beyeme-Ondoua (2002). Le système de santé camerounais. Actualité et dossier en santé publique.39.pp.61-5.

7. A.M. Agbor, C.C. Azodo, S. Naidoo. The Oral Health workforce in Cameroon; the past, the present and the future. African Journal of oral health $2018 ; 7(2): 1-9$

8. L.N. Achembong, A.M. Ashu, A. Hagopian, A. Downer, S .Barnhart (2012). Cameroon mid-level providers offer a promising public health dentistry model. Human Resources for Health.pp 10:46.

9. C.C. Azodo, M.A. Agbor (2015). Prevalence and unmet treatment needs of traumatized incisors among Cameroonian school children in North West Province. OdontoStomatologie Tropicale.38(132).pp.1-6.

10. Index Mundi. Cameroon Demographics Profile 2017. https://www.indexmundi.com/cameroon/demographics_profile.html. (visited 20/10/2019)

11. T. Attin, F.N. Mbiydzemo, I. Villard, A.M. Kielbassa, E. Hellwig (1999). Dental status of schoolchildren from a rural community in Cameroon. S Afr Dent J. 54.pp.145-8.

12. P. Gupta, N. Gupta, P.A. Pawar, S.S. Birajdar, A. S. Natt, H. P. Singh (2013).Role of Sugar and Sugar Substitutes in Dental Caries: A Review. ISRN Dentistry. (1). Pp.1-5.

13. B.F. Songo, D. Declerck, F.Vinckier, M.D. Mbuyi, C.M.Pilipili, K.P. Kayembe (Dec. 2013). Caries experience and related factors in 4-6 year-olds attending dental clinics in Kinshasa, DR of Congo. Community Dent Health.30(4).pp.257-62.

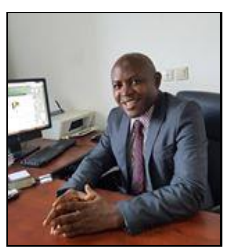

Dr. Ashu Michael Agbor is an Associate Professor in community oral health and Dean of the Université des Montagnes dental school, Bangangté -Cameroon. He studied dentistry at University of Benin dental school, Nigeria where he obtained his bachelor of dental surgery (BDS) in the year 2001. He is a holder of a post graduate diploma in community oral health at Radboard University, Nigmegen- Holland 2007. He obtained a masters in dental public health in 2009 at the University of the Western Cape in South Africa and also a PhD in Community oral health at the University of the Western Cape in 2015. He is a fellow and master of oral implantology from the ICOI (international congress of oral implantology since 2013 ). $\mathrm{He}$ also a holder of a post doctorate certificate of competence in doctoral supervision for doctoral candidates in African Universities from Stellenbosch University since 2019 and also a fellow of the international college of dentist since 2011 .

His a researcher in basic and clinical oral health. He has published widely on indigenous oral medicine, oral biology, dental education and community oral health. He has pioneer many community oral health programs in Cameroon.

Dr. Tchuanche Kuimo Raissa is a clinical assistant at the Universite des Montagnes teaching hospital . she obtained her DDS in dentistry from Université des Montagnes 2015. 